\title{
Pearl Mullet (Alburnus tarichi (Guldenstaedtii, 1814)) Fishing with Trammel Nets in Lake Van
}

\author{
Adem Sezai BOZAOĞLU1, Mustafa AKKUŞ11, Adiyet YEŞíL1 \\ ${ }^{1}$ Avlama ve İşleme Teknolojisi Bölümü Su Ürünleri Fakültesi Van Yüzüncü Yıl Üniversitesi, Van, Türkiye \\ ORCID ID: Adem Sezai BOZAOĞLU: https:// orcid.org/0000-0002-3942-659X; Mustafa AKKUŞ: https://orcid.org/0000-0002-8900-9495; \\ Aidiyet YEŞIL: https:// orcid.org/0000-0002-1020-0407
}

\begin{abstract}
Received: 31.03.2019 Accepted: 08.06.2019 Published online: $30.06 .2019 \quad$ Issue published: 30.06 .2019
Abstract: This study was conducted with the contributions of 77 interview participants to determine the characteristics of the trammel net and fishing boats, problems of fishermen, and the landing amount of pearl mullet (Alburnus tarichi, Güldenstädt, 1814) captured in Lake Van between 2016 and 2017. According to the results, it was found out that trammel nets were the only fishing gear that are used by fishermen on pearl mullet fishing in Lake Van. In terms of the FAO standards, it was found out that the technical plans of trammel nets were drawn accordingly, and a fishing boat uses an average of $4393 \mathrm{~m}$ of trammel net. In addition, it was determined that the fishing boats used in pearl mullet fishery in Lake Van had an average engine power of $92 \pm 36.75 \mathrm{BG}$ and the average length of the boats was $12 \pm 2.25 \mathrm{~m}$. Furthermore, the most important problems of fishermen were named as illegal, uncontrolled, and unregulated (IUU) fishing, low fish prices, and lack of harbor facilities.
\end{abstract}

Keywords: Van lake, Pearl mullet, trammel nets, fishing.

\section{Van Gölü'nde Fanyalı Uzatma Ağları ile İnci Kefali (Alburnus tarichi (Guldenstaedtii, 1814))} Avcılığı

Öz: Bu çalışma, Van Gölü inci kefali (Alburnus tarichi, Güldenstädt, 1814) avcılığında kullanılan fanyalı uzatma ağları ve balıkçı teknelerinin özelliklerini, avlanan inci kefali miktarını ve balıkçıların sorunlarını belirlemek için 2016-2017 yılları arasında, 77 kişiyle anket görüşmesi yapılarak gerçekleştirilmiştir. Araştırmada inci kefali avcılığında sadece fanyalı uzatma ağlarının kullanıldığı saptanmıştır. Ağların teknik planı FAO standartlarına göre tanımlanmış ve Van Gölü'nde bir balıkçı teknesinin ortalama 4393 m fanyalı uzatma ağı kullandığı saptanmıştır. İnci kefali avcılığında kullanılan balıkçı teknelerinin ortalama $92 \pm 36.75$ BG motor gücüne sahip olduğu ve teknelerin ortalama uzunluklarının 12 $\pm 2,25$ m olduğu tespit edilmiştir. Balıkçıların en önemli sorunlarının yasadışı avcılık, balık fiyatlarının düşük olması ve çekek yeri sorunu olduğu sonucuna varılmıştır.

Anahtar kelimeler: Van Gölü, inci kefali, fanyalı uzatma ağı, balıkçılık.

\section{Giriş}

Balıkçılık, günümüzde en önemli ekonomik faaliyetlerin başında gelmektedir (Aure et al., 2018). Son yıllarda ülkemiz ve dünyada balık stokları üzerinde oluşan aşırı av baskısı birçok stoku çökertme noktasına getirmiştir (Williams, 1998; Mullon, Freon, \& Cury, 2005; Kılıç, 2014). $\mathrm{Bu}$ durum balıkçılık yönetimi açısından, stokların sürdürülebilir yönetime kavuşturulmasında balıkçılığa ilişkin av araçlarının yapısının ve balıkçılığın mevcut durumunun bilinmesinde önemlidir. Ülkemizde balıkçılıkta denizler ön planda olmasına karşın önemli bir miktarda iç sulardan avcılık yolu ile ürün elde edilmektedir. Bu üretimdeki en büyük pay Van Gölü İnci Kefali balıkçılığına aittir. Van Gölü 3547 km² yüzey alanı, $607 \mathrm{~km}^{3}$ toplam hacmi ve $450 \mathrm{~m}$ maksimum derinliğe sahip Türkiye'nin en büyük gölüdür. Van Gölü, yüksek oranda alkali karakterde olup, soda miktarı yüksektir. Gölün pH değeri 9.5'ten fazla, tuzluluğu ise \%o 21.28 olarak hesaplanmıştır (Sarı, 1997). Ekstrem bir su kalitesine sahip bu gölde, ekonomik değere sahip ve avcılığı yapılan tek balık türü inci kefalidir. Van Gölü havzası su kaynaklarında yayılış gösteren inci kefali, ekonomik ve endemik bir tür olması nedeniyle hem ülkemiz hem de bölge için büyük bir önem arz etmektedir. TÜİK verileri incelendiğinde avcılık yoluyla üretilen iç su balıkları üretimi 2016 yılında 32145 ton olarak gerçekleşmiştir. Bu miktarın 9830 tonunu inci kefali oluşturmaktadır. Türkiye İstatistik Kurumu verilerine göre 7545 adet uzatma ağı teknesi vardır (TÜİK, 2017). Su Ürünleri Bilgi İşlem Sistemi (SUBİS) kayıtlarına göre 2018 yılında Van iline kayıtlı 82, Bitlis iline kayıtlı 19 ruhsatlı balıkçı teknesi bulunmaktadır. Uzatma ağları teknik özellikleri bakımından birçok farklılıklar göstermektedir (Özyurt, Kiyağa, \& Akamca, 2008; Ay \& Duman, 2015). Fakat genel olarak, fanyalı ve sade olmak üzere iki grupta sinıflandırılmaktadır (Özdemir \& Erdem, 2006). Balıkçılıkta sürdürülebilir bir yönetim için, avcılıkla ilgili birçok verinin bilinmesi gerekmektedir. Ülkemizin önemli balıkçılık kaynaklarından olan Van Gölü balıkçılığı ile ilgili az sayıda çalışma yapılmıştır (Çetinkaya, Sarı, \& Arabacı, 1995; Sarı, 1997; Sarı, 2008). Bu çalışmalar seçicilik, üreme dönemi sorunları ve stok tahminine yönelik çalışmalar olup balıkçıları dikkate almamaktadır. Ayrıca aradan geçen süre içerisinde balıkçılığın dinamik doğası nedeniyle ağların teknik özellikleri ile ilgili bilgiler güncelliğini kaybetmiştir. Alanda yapılan teknik ölçümler ile Van Gölü İnci Kefali avcılığında kullanılan fanyalı uzatma ağların teknik özellikleri tespit edilmiştir. Bunun yanında balıkçı teknelerinin özellikleri ve avlanan inci 
kefali miktarı da belirlenmiştir. Ayrıca balıkçılara uygulanan anket ile balıkçıların sorunları ve beklentileri belirlenmiştir. Elde edilen veriler balıkçıllk yönetimi açısından değerlendirilerek çözüm önerileri sunulmuştur.

\section{Materyal ve Yöntem}

Bu çalışma 2016-2017 yıllarında Van Gölü kıyısında yer alan, Gevaş, Çitören, Dağönü, Tatvan ve Edremit balıkçı barınaklarında yürütülmüştür (Şekil 1). Çalışmada, avcılıkta kullanılan fanyalı uzatma ağları, avcılığın yapıldığ1 teknelerin özellikleri belirlenmiştir. Ayrıca barınaklarda bulunan toplam 77 balıkçı ile yüz yüze anket gerçekleştirilmiştir. Ankette her bir balıkçının avladığı inci kefali miktarı ve sorunları belirlenmiştir. Tespit edilen fanyalı uzatma ağının teknik planı FAO standartlarına göre tanımlanmış ve Corel Draw 2011 programı kullanılarak ağın teknik planı çizilmiştir. Çalışmada Van Gölü balıkçı barınaklarına göre; uzatma ağlarının uzunlukları, tekne boyları ve motor güçlerinin karşılaştırılmasında varyans analizi kullanılmıştır. Önemli bulunan farklılıkları belirlemek için Duncan çoklu karşılaştırma testi uygulanmıştır. Araştırma kapsamında elde edilen veriler SPSS 17 istatistik yazılım programında değerlendirilmiştir.

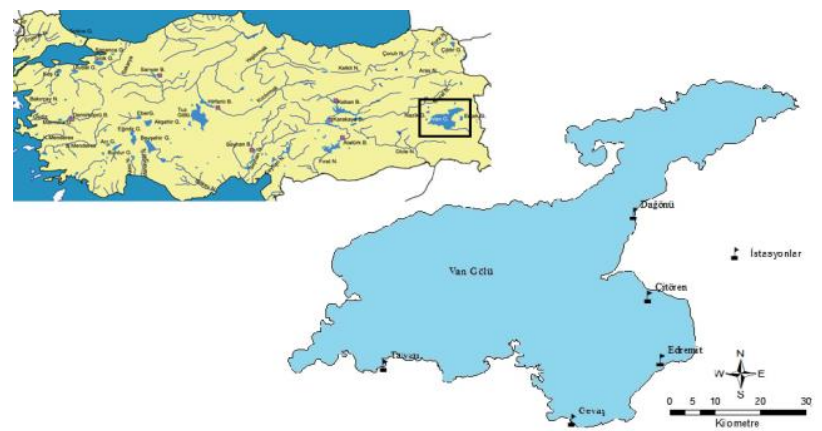

Şekil 1: Araştırma bölgesi.

\section{Bulgular}

\subsection{Teknelerin Özellikleri}

Anketler Gevaş, Çitören, Dağönü, Tatvan ve Edremit balıkçı barınaklarını kullanan tekne kaptanlarıyla yapılmıştır. Yapılan anket sonuçlarına göre tekneler ortalama $14 \pm 6.87$ yaş, $12 \pm 2.25 \mathrm{~m}$ boy ve $92 \pm 36.75$ BG motor gücüne sahip olduğu saptanmıştır. Teknelerin tamamının sacdan yapıldı̆̆ 1 belirlenmiştir. Teknelerin tümünde ağların tekneye çekilmesinde kullanılan ağ tamburu bulunduğu tespit edilmiştir.

\subsection{Fanyalı Uzatma Ağları}

Van Gölü'nde bir balıkçı teknesi tarafından ortalama $4393 \pm 120$ m fanyalı uzatma ağı kullanıldığı saptanmıştır. İnci kefali avcılığında kullanılan bu ağların $\mathrm{E}=0.50$ ya da $E=0.40$ donam faktörü ile donatıldığı belirlenmiştir. Fanyalı ağların bir postası, $100 \mathrm{~m}$ uzunluğunda ve torun her iki tarafında balığın dolanarak yakalanmasını sağlayan fanya bulunmaktadır. Fanyalı ağların donatılmasında kullanilan tor kisımları 110 denye 2 numara ip kalınlığında, Poliamid (PA), $44 \mathrm{~mm}$ göz açıklığında ve 60 göz derinliğindedir. Fanyalar ise, 210 denye 3 numara ip kalınlığında, PA, $250 \mathrm{~mm}$ göz açıklığında ve 5 göz derinliğindedir. Mantar yakada $100 \mathrm{~m}$ uzunluğunda Polipropilen (PP) Ø $5 \mathrm{~mm}$ çaplı ana halat ile 119 adet plastik (Pl) 3 numara siyah renkli yüzdürücü kullanıldığ1 saptanmıştır. Kurşun yakada, 102 m uzunluğunda Polipropilen (PP), $5 \mathrm{~mm}$ çaplı ana halat ve PP $\varnothing 4 \mathrm{~mm}$ çaplı koşma halatı ile 278 adet 50 gr ağırlığında kurşun kullanılmaktadır. Bu uzatma ağ1 mantar yakaya, $\mathrm{E}=0.50$ kurşun yakaya ise $\mathrm{E}=0.51$ donam faktörü ile donatılmıştır. Çaka boyunun mantar yakada $120 \mathrm{~mm}$, kurşun yakada ise $122 \mathrm{~mm}$ olduğu tespit edilmiştir (Şekil 2).

Donam faktörü $E=0.4$ olarak belirlenen fanyalı ağlar, donam faktörü $E=0.5$ olarak belirlenen ağlar ile benzer özelliklere sahiptir. Bu uzatma ağları mantar yakaya \%40, kurşun yakaya ise \%41 donam faktörü ile donatılmıştır. Mantar yakada çako boyunun $96 \mathrm{~mm}$, kurşun yakada ise $98 \mathrm{~mm}$ olduğu tespit edilmiştir. (Şekil 3).

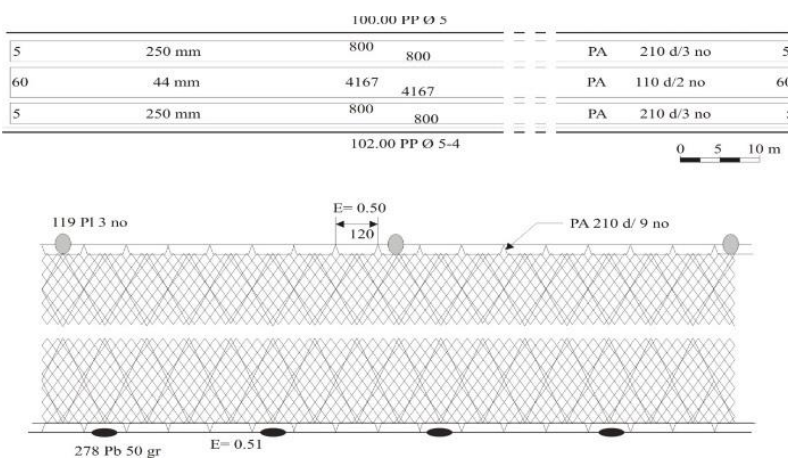

Şekil 2: Donam faktörü $E=0.50$ olan fanyalı ağların teknik özellikleri ve ağın kesiti.
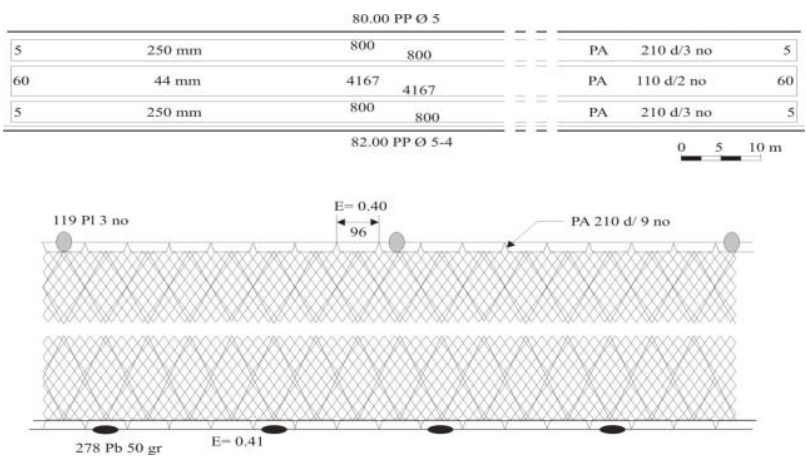

Şekil 3: Donam faktörü $E=0.40$ olan fanyalı ağların teknik özellikleri ve ağın kesiti.

\subsection{Av Operasyonu}

İnci kefali avcılığ 15 Nisan-15 Temmuz tarihleri arasında yasaktır. Avcılığın serbest olduğu dönemlerde ise sadece fanyalı ağlar ile inci kefali avcılığına izin verilmektedir. Balıkçılarla yapılan anket sonuçlarına göre, ağların ortalama 24 saat suda kaldığ 1 tespit edilmiştir. Sabah saat 07.00 'de göle birakılan ağlar ertesi sabah saat 07.00 'de kaldırılmaktadır. Bahar aylarının başında tatlı sulara göç eden inci kefalleri, yumurtlama sonrası yaz aylarında göle geri dönerler. Önceleri kıyıya yakın yerlerde bulunan inci kefalleri, balıkların mevsimsel derinlik göçlerine bağlı olarak suların soğumasıyla birlikte derinlere inerler. Balıkçıların da bu göçe paralel olarak ağlarını 10-120 kulaç arasında değişen derinliklere bıraktıkları belirlenmiştir. Bilindiği üzere Van Gölü'nde sadece inci kefali avcıllı̆̆ yapılmaktadır. Yapılan anketlerle yöneltilen sorulara 
balıkçıların vermiş oldukları cevaplara göre yıllık 8000 ton inci kefalinin avlandığı belirlenmiştir.

\subsection{Tekne Başına Birim Ağ Uzunluğu}

Van Gölü balıkçı barınaklarında kullanılan fanyalı ağların miktarı bakımından balıkçı barınakları arasındaki fark istatistiksel olarak anlamlı bulunmuştur $(\mathrm{p}<0.01)$. Tekne başına kullanılan en fazla ağ miktarı, Dağönü balıkçı barınağında $5166.67 \pm 22 \mathrm{~m}$ olarak tespit edilirken, en az ağ Tatvan balıkçı barınağında $3390 \pm 113 \mathrm{~m}$ olarak saptanmıştır. Diğer balıkçı barınaklarında ise sırası ile Gevaş balıkçı barınağı $(4833 \pm 141 \mathrm{~m})$, Çitören balıkçı barınağ 1 (3709 $\pm 83 \mathrm{~m})$, Edremit balıkçı barınağ $(3450 \pm 892$ m) olarak izlenmiştir. (Şekil 4).

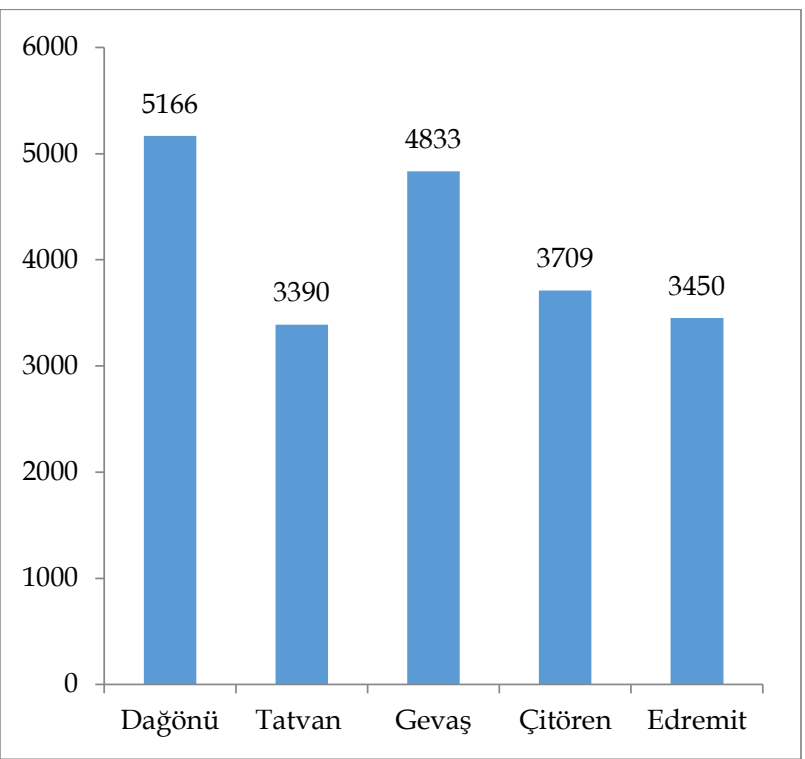

Şekil 4: Van Gölü'nde tekne başına kullanılan fanyalı ağ uzunluklarının (m) balıkçı barınaklarına göre değişimi.

\subsection{Tekne Boyları}

Tekne boyu değişkeni bakımından balıkçı barınakları arasındaki fark istatistiksel olarak anlamlı bulunmuştur $(\mathrm{p}<0.05)$. En uzun tekne boyu Çitören balıkçı barınağında $13.91 \pm 2.36 \mathrm{~m}$, en kısa tekne boyu ise Gevaş balıkçı barınağında ortalama $11.88 \pm 2.39$ m olarak tespit edilmiştir. Diğerleri ise sırasıyla; Edremit balıkçı barınağında $13.55 \pm 2.54 \mathrm{~m}$, Dağönü balıkçı barınağında $13.36 \pm 1.18 \mathrm{~m}$ ve Tatvan balıkçı barınağında $13.20 \pm 1.29 \mathrm{~m}$ olarak belirlenmiştir (Şekil 5).

\subsection{Tekne Motor Güçleri}

Motor gücü bakımından balıkçı barınakları arasındaki fark istatistiksel olarak anlamlı bulunmamıştır $(\mathrm{p}>0.05)$. Ortalama motor güçleri karşılaştırıldığında en yüksek

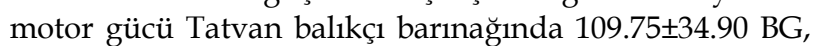

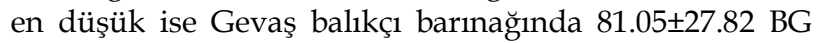
olarak tespit edilmiştir. Diğer barınaklardaki ortalama

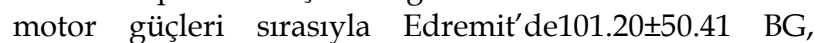
Dağönü balıkçı barınağında 99.18 \pm 51.50 BG, Çitören balıkçı barınağında ise $96.12 \pm 21.20$ BG olarak belirlenmiştir. (Şekil 6).

\subsection{Başlıca Sorunlar}

Van Gölü balıkçılığında karşılaşılan en önemli sorununun üreme göçü döneminde derelerde yapılan kaçak avcılık olduğu belirlenmiştir. Bu dönemde özellikle manyat ve monoflament misina ağların üreme döneminde yasa dışı olarak kullanıldığı tespit edilmiştir. Bir diğer sorun ise avlanan balığın değerinin altında satılması olarak ifade edilmiştir. Anket sonuçlarına göre balığın toptan fiyatının 2-3.5 TL arasında olduğu tespit edilirken, balıkçılar çoğu zaman masraflarını karşılamakta zorlandıklarını beyan etmişlerdir. Bir diğer sorunun da balıkçı barınaklarında çekek yerlerinin bulunmaması olarak ifade edilmiştir.

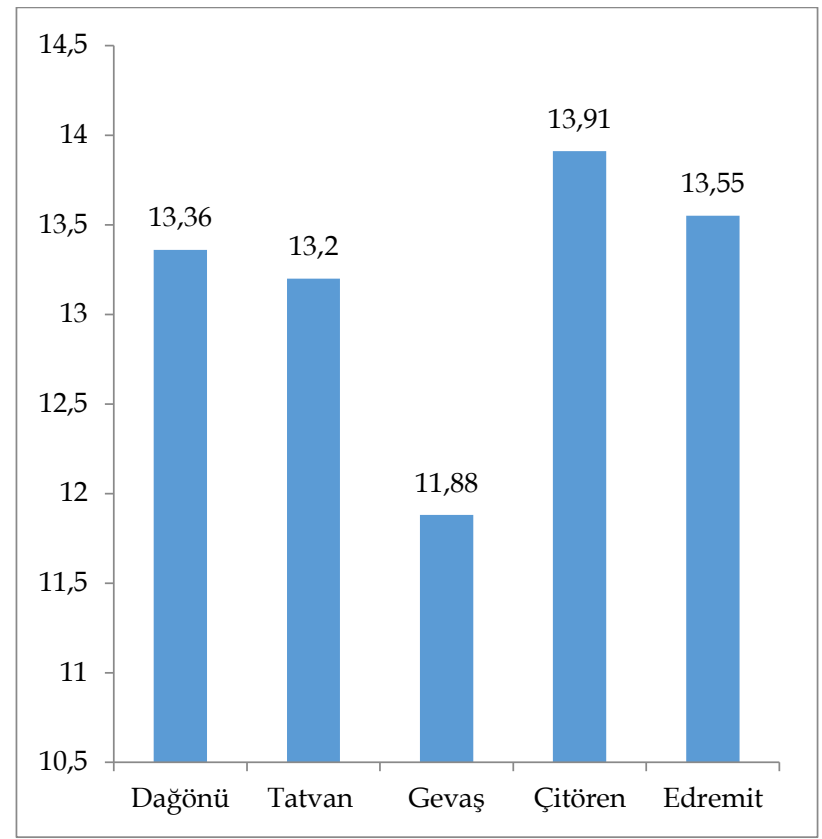

Şekil 5: Van Gölü balıkçı barınaklarındaki ortalama tekne boyları (m).

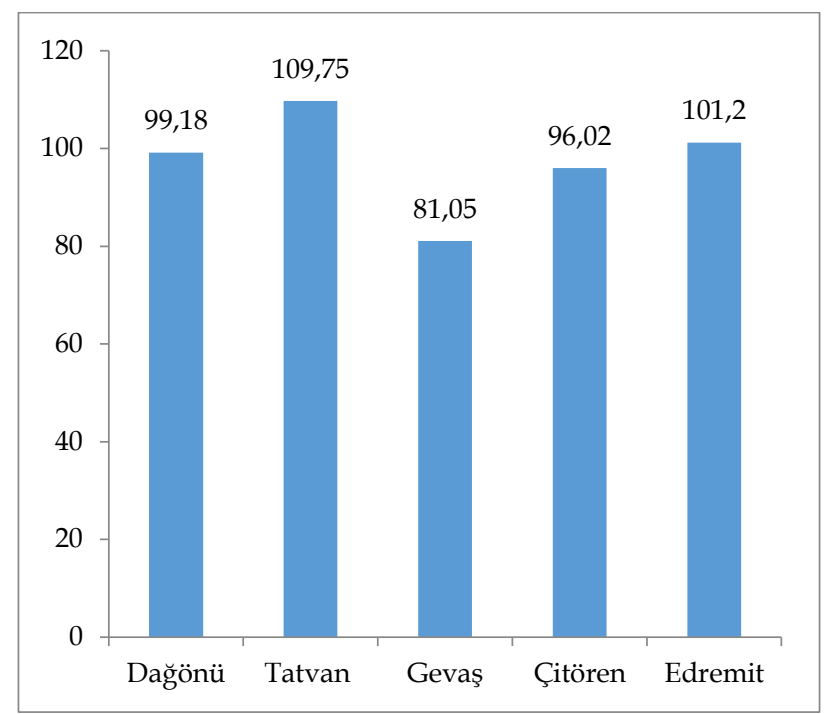

Şekil 6: Van Gölü balıkçı barınaklarındaki teknelerin ortalama motor güçleri (BG).

\section{Tartışma ve Sonuç}

Bu çalışma, Van Gölü balıkçılığın sürdürülebilir bir yapıya kavuşturulması için gerekli verilerin elde edilmesi amacıyla yapılmıştır. Yapılan anket sonuçlarına göre bölgede, $44 \mathrm{~mm}$ ağ göz açıklığında, $\mathrm{E}=0.40$ ve $\mathrm{E}=0.5$ donam faktörü ile donatılmış iki farklı fanyalı ağ kullanıldığı tespit edilmiştir. Sazan ve siraz avcılığında genellikle 50-80 mm ağ göz açıklığı arasında multiflament özelliğe sahip uzatma ağları kullanılmaktadır (Çınar 2010; Şen 2016; Cilbiz, Küçükkara, Ceylan, Savaşer, \& Meke, 
2015). Van Gölü'nde Cetinkaya et al. (1995), tarafından yapılan çalışmada, inci kefali avcılığında $34 \mathrm{~mm}$ ve $40 \mathrm{~mm}$ göz açıklığındaki ağların kullanıldığı bildirilmiştir. İnci kefali avcılığında geçmişte kullanılan ağ göz açıklığının, günümüzde kullanılanlara göre $10 \mathrm{~mm}$ daha küçük olması, son yıllarda balık boylarının arttığını göstermektedir. Bunun da üreme göçü döneminde yapılan yasadışı avcılıktan kaynaklandığ 1 düşünülmektedir. Stoklardaki balıkların boyca küçülmesi aşırı avcılığın en belirgin göstergesidir (Avşar, 2005). Avcılıkta kullanılan ağ göz açıklığının aradan geçen 23 yıl içerisinde $10 \mathrm{~mm}$ arttığı görülmüştür. Bu durum balığın boyca ve ağırlıkça büyüdüğünün bir göstergesidir. Bu durumun son yıllarda 15 Nisan-15 Temmuz tarihleri arasında inci kefali üreme döneminde yapılan koruma çalışmalarından kaynaklandığı düşünülmektedir. Uzatma ağlarının donatılmasında seçilen donam özellikleri avlanan ürünün büyüklüğü ve miktarı üzerinde etkilidir. Yapılan bu çalışmada, bazı balıkçıların $\mathrm{E}=0.50$ bazı balıkçıların ise $\mathrm{E}=$ 0.40 donam faktörü kullanıldığı tespit edilmiştir. Özellikle $\mathrm{E}=0.40$ donama sahip ağların kullanılması inci kefalinin birçok tatlı su balığı türüne göre daha aktif bir tür olmasından kaynaklanmaktadır. Çünkü inci kefali de her ne kadar Cyprinidae ailesinden olsa da daha çok fusiform bir yapıda ve çok hızlı bir balıktır (Gündoğdu, 2010). Hareketli balıkların ağ gözlerine takılarak başından ya da galsamasından yakalandığı ağlar daha küçük donam faktörü uygulanarak, diğer bir deyişle daha gergin donatılmaktadır (Tokaç, 2010). Zira Machiels et al. (1994), yapmış oldukları bir çalışmada sudak (Lucioperca lucioperca) ve çapak (Abramis brama Linnaeus, 1758) balıklarının avcılığında kullandıkları 0.25 donam faktörü ile donatılmış olan ağların 0.5 donam faktörü ile donatılmış ağlara göre daha etkin avcılık yaptığını belirtmişlerdir. $\mathrm{Bu}$ nedenle kullanılan fanyalı uzatma ağlarının $E=0.40$ donam faktörü ile donatılmasının yaygınlaştığ1 düşünülmektedir. Bu ağlar, bölgede ağ1 donatacak kişi olmadığ 1 için farklı bölgelerden donatılmış olarak getirilerek kullanılmaktadır. Anket sonuçlarına göre, bu ağlar Trabzon ve Adana bölgesinden getirtilmektedir. Ağlar farklı bölgelerden getirildiği için balıkçı barınakları arasında, istatistiksel olarak tespit edilen fark beklenen bir durumdur. $\mathrm{Bu}$ verilere göre; teknelerin ortalama boyu $12.75 \pm 2.25 \mathrm{~m}$, kullanilan motorların ortalama gücü ise $92.29 \pm 36.75$ BG olarak tespit edilmiştir. Ural ve Canpolatı (2009), Doğu ve Güneydoğu Anadolu Bölgelerinde yaptıkları bir çalışmada balıkçı teknelerinde kullanılan motorların güçlerinin minimum 411 ile maksimum 8-100 BG arasında değiştiğini tespit etmişlerdir. Aynı çalışmada balıkçı teknelerinin boyları ise 4-12 m arasında olduğu bildirilmiştir. Bu çalışmadaki bulgularla bizim çalışmamızın verileri örtüşmemektedir. Bunun en önemli nedeni gerek denizlerde gerekse iç sularda teknelerin büyük bir kısmı ahşaptan yapılırken, Van Gölü'ndeki tüm tekneler ise sac (metal) malzemeden yapılmaktadır. Ayrıca Van Gölü 3547 km² yüzey alanına sahip olması nedeni ile küçük sucul ekosistemlere göre daha uzun ve motor gücü daha yüksek teknelerin kullanımını gerektirmektedir. Dolayısıyla gerek göl yüzey alanının büyüklügü ve gerekse saç teknelerin kullanılması daha güçlü motorların kullanılmasını zorunlu kılmaktadır. Tekne büyüklüğü bakımından özellikle Gevaş balıkçı barınağı ile Çitören balıkçı barınağı arasındaki farklılık tespit edilmiştir. Van Gölü'nde sadece
Gevaş balıkçı barınağında bir balıkçılık kooperatifi bulunduğundan en fazla tekne bu barınakta bulunmaktadır. Buradaki teknelerden bazılarının küçük olması ortalamayı düşürdüğünden, istatistiksel olarak bir fark ortaya çıkmaktadır.

Balıkçıların verdiği cevaplar sonucunda Van Gölünde yıllık yaklaşık 8.000 ton inci kefali avlandığ belirlenmiştir. Fakat TUİK (2017) verilerine göre inci kefali av miktarı 9.830 tondur. Göldeki tüm tekne sahipleriyle anket yapılmadığı için bu rakamın daha düş̧ük olması beklenen bir durumdur. Van Gölü'nde balıkçılarla yapılan yüz yüze anket sonuçlarına göre balıkçıların en önemli sorunları üreme dönemlerinde derelerde yapılan yasadışı avcılık, avladıkları balığın değerinin altında satılması ve barınak oluşturmaktadır. Anket sonuçlarına göre özellikle üreme dönemi olan 15 Nisan-15 Temmuz ayları arasında manyat ve uzatma ağlar ile yasadışı avcılık yapıldığı saptanmıştır. Yasa dişı yapılan bu avcılık Van Gölü İnci Kefali stokuna ciddi zarar verdiği için yasal olarak bu işi yapan balıkçıların bu durumdan şikâyetçi oldukları belirlenmiştir. Bu konunun çözümü için kontrollerin arttırılması, daha caydırıcı cezaların uygulanması ve toplumun bilinçlendirilmesi ile bu sorunun bir nebze çözüleceği kanaatindeyiz. Avlanan balığın düşük fiyata satılması bir diğer sorun olarak karşımıza çıkmaktadır. Bu durum için de balıkçıların bir araya gelerek ortak hareket etmeleri, bir balık halinin açılması veya balığa alternatif bir pazar bulunması sorunun çözümü için bir seçenek olabilir. Çekek yerinin olmaması balıkçıların diğer bir sorunu olarak karşımıza çıkmaktadır. Bunun için de öncelikli olarak mevcut barınaklara çekek yerleri yapılabilir. Unutulmamalıdır ki anket verileri tamamen balıkçılarla yüz yüze görüşme neticesinde alınmış bilgilerdir. Olası bir yer, zaman veya kullanılan av araç gerecinin miktarında yapılacak yasak ya da bir kisitlama durumunda ilgili yöneticilerin öncelikle yerinde araştırma yaparak durumu tespit etmeleri ve gerekirse balıkçının resmi beyanlarından yararlanmaları daha akılcı bir yaklaşım olacaktır.

Teşekkür: Bu çalışmanın gerçekleştirilmesinde yardımlarını esirgemeyen Van Gölü uzatma ağı tekneleri kaptanlarına ve tayfalarına teşekkür ederiz. Ayrıca bu çalışma Van Yüzüncü Yıl Üniversitesi Bilimsel Araştırmalar Projeler Bölümü (BAP FYL2017-5865) tarafından desteklenmiştir.

\section{Kaynaklar}

Aura, C.M., Nyamweya, C.S., Niiru, J.M., Musa, S., Ogari, Z., May, L., \& Wakwabi, E. (2018). Exploring the demarcation requirements of fish breeding and nursery sites to balance the exploitation, management and conservation needs of Lake Victoria ecosystem. Fisheries Management and Ecology, 2018, 1-9.

Avşar, D. (2005). Balıkçılık Biyolojisi ve Popülasyon Dinamiği. Adana, Türkiye, Nobel Yayın Evi, 332 pp

Ay, A., \& Duman E. (2015). Rize İlinde Kullanılan Uzatma Ağlarının Teknik Özelliklerinin Belirlenmesi. Firat Üniversitesi Fen Bilimleri Dergisi, 27(1), 35-48.

Cilbiz, M., Küçükkara, R., Ceylan, M., Savaşer, S., \& Meke, T. (2015). Trammel net selectivity of common Carp (Cyprinus carpio L., 1758) in Manyas Lake, Turkey. Journal of Limnology and Freshwater Fisheries Research, 1(1), 1-7.

Çetinkaya, O., Sarı, M., \& Arabacı, M. (1995). Van Gölü (Türkiye) İnci Kefali (Chalcalburnus tarichi, Pallas 1811) Avcılığında Kullanılan Fanyalı Uzatma Ağlarının Av Verimi ve Seçiciliği Üzerine Bir Ön Çalışma. Ege Üniversitesi Su Ürünleri Dergisi, 12(1-2), 1-13.

Çınar, S. (2010). Eğirdir Gölünde Monofilament (Tek Kat) ve Multifilament (Çok Kat) Fanyalı Ağların Av Verimlerinin karşılaştırılması (Yüksek Lisans Tezi). Süleyman Demirel Üniversitesi, Isparta, Türkiye. 
Gündoğdu, S. (2010). Erçek Gölü İnci Kefali (Chalcalburnus tarichi, Pallas 1811) Populasyonu Üzerine Bir Araştırma (Yüksek Lisans Tezi). Yüzüncü Yıl Üniversitesi, Van, Türkiye.

Kılıç, S. (2014). Türkiye Denizlerindeki Balık Stoklarının Yönetimi İçin Yeni Bir Kavram: 'İhtiyatlı Balıkçılık Yönetimi'. Yunus Araştırma Bülteni, (4), 85-97.

Machiels, M.A., Kling, M., Lanters, R., \& Van den-sen, W.L. (1994). Effect of snood Length and hanging ratio on effectivitiy and selectivity of bottom-set gillnets for pikeperch (Stizostedion lucioperca) and bream (Abramis brama). Journal of Fisheries Research, 19, 231-239.

Mullon, C., Freon, P., \& Cury, P. (2005). The dynamics of collapse in world fisheries. Fish and fisheries, 6(2), 111-120.

Özdemir, S., \& Erdem, Y. (2006). The comparasion of catch efficiency of mono and multifilament gillnets on different weather conditions. Science and Engineering Journal of Firat University, 18(1), 63-68.

Özyurt, C.E., Kiyağa, V.B., \& Akamca E. (2008). İskenderun Körfezi'nde Fanyalı Uzatma Ağları ile Dil Balığı Avcılığı. Ege Üniversitesi Su Ürünleri Dergisi, 3, 233-237

Sarı, M. (1997). Van Gölü İnci Kefalinin Stok Miktarının Tahmini ve Balıkçılık Yönetim Esaslarının Belirlenmesi (Doktora Tezi). Ege Üniversitesi, İzmir, Türkiye.

Sarı, M. (2008). Threatened fishes of the world: Chalcalburnus tarichi (Pallas 1811) (Cyprinidae) living in the highly alkaline Lake Van, Turkey. Environmental biology of fishes, 81(1), 21-23.

SUBİS, (2018). Su Ürünleri Bilgi İşlem Sistemi, Van. (Erişim Tarihi 20 Eylül 2018)

Şen, Y. (2016). Demirköprü Baraj Gölü'nde Sazan (Cyprinus carpio L., 1758) Türü İçin Kullanılan Uzatma Ağlarının Av Verimliliği ve Seçiciliğinin Belirlenmesi (Yüksek Lisans Tezi). Izmir Katip Çelebi Üniversitesi, İzmir, Türkiye.

Tokaç, A. (2010). A ̆̆ Yapım ve Donam Tekniği: Balıkçılık 2. İzmir, Türkiye, Ege Üniversitesi Yayınları, 321 pp.

TÜIK, (2017). Türkiye İstatistik kurumu. www.tuik.gov.tr. (Erişim Tarihi: 20 Nisan 2018).

Ural, M., \& Canpolatı, İ. (2009). Doğu ve GAB. Su Ürünleri Kooperatiflerinin Yapısı ve Av Araçları ile Balıkçı Teknelerinin Teknik Özellikleri. TÜBAV Bilim Dergisi, 2(4), 372-384.

Williams, N. (1998). Overfishing Disrupts Entire Ecosystems. Sciences, 279, 50352-809. 